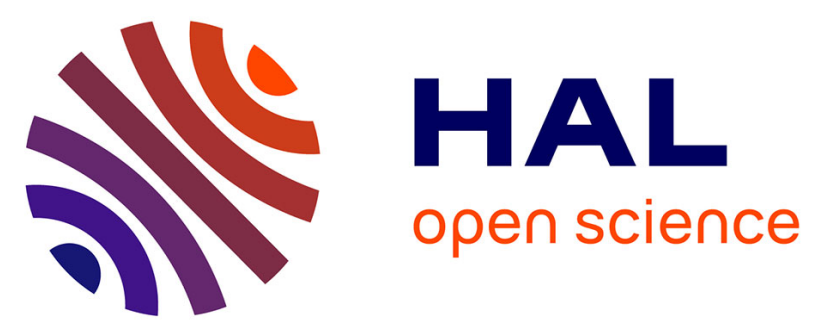

\title{
Lagrangian measurements of the fast evaporation of falling diethyl ether droplets using in-line digital holography and a high-speed camera
}

Jean-Louis Marié, Nathalie Grosjean, Loïc Méès, Mozhdeh Seifi, Corinne Fournier, Bernard Barbier, Michel Lance

\section{To cite this version:}

Jean-Louis Marié, Nathalie Grosjean, Loïc Méès, Mozhdeh Seifi, Corinne Fournier, et al.. Lagrangian measurements of the fast evaporation of falling diethyl ether droplets using in-line digital holography and a high-speed camera. Experiments in Fluids, 2014, 55, 1708 (13 p.). 10.1007/s00348-014-1708-6 . ujm-01020697

\section{HAL Id: ujm-01020697}

\section{https://hal-ujm.archives-ouvertes.fr/ujm-01020697}

Submitted on 22 Jun 2015

HAL is a multi-disciplinary open access archive for the deposit and dissemination of scientific research documents, whether they are published or not. The documents may come from teaching and research institutions in France or abroad, or from public or private research centers.
L'archive ouverte pluridisciplinaire HAL, est destinée au dépôt et à la diffusion de documents scientifiques de niveau recherche, publiés ou non, émanant des établissements d'enseignement et de recherche français ou étrangers, des laboratoires publics ou privés. 


\title{
Lagrangian measurements of the fast evaporation of falling Diethyl Ether droplets using in-line digital holography and a high-speed camera
}

\author{
J.L. Marié • N. Grosjean • L. Méès · M. Seifi • C. Fournier • B. \\ Barbier . M. Lance
}

March 10, 2014

\begin{abstract}
The evaporation of falling Diethyl Ether droplets is measured by following droplets along their trajectories. Measurements are performed at ambient temperature and pressure by using in-line digital holography. The holograms of droplets are recorded with a single high-speed camera and reconstructed with an "inverse problems" approach algorithm previously tested (Chareyron et al 2012). Once evaporation starts, the interfaces of the droplets are surrounded by air/vapor mixtures with refractive index gradients that modify the holograms. The central part of the droplets holograms is unusually bright compared to what is expected and observed for non-evaporating droplets. The reconstruction process is accordingly adapted to measure the droplets diameter along their trajectory. The Diethyl Ether being volatile, the droplets are found to evaporate in a very short time: of the order of $70 \mathrm{~ms}$ for a $50-60 \mu \mathrm{m}$ diameter at an ambient temperature of $25^{\circ} \mathrm{C}$. After this time, the Diethyl Ether has fully evaporated and droplets diameter reaches a plateau. The remaining droplets are then only composed of water, originating from the cooling and condensation of the humid air at the droplet surface. This assertion is supported by two pieces of evidence: (i) by estimating the evolution of droplets refractive index from light scattering measurements at rainbow angle, and (ii) by
\end{abstract}

J.L. Marié · N. Grosjean · L. Méès · B. Barbier · M. Lance Laboratoire de Mécanique des Fluides et d'Acoustique UMR5509, Ecole Centrale de Lyon - CNRS - Université Claude Bernard Lyon 1 - INSA Lyon,

36 avenue Guy de Collongue, 69134 Ecully cedex, France Email: jean-louis.marie@ec-lyon.fr

M. Seifi · C. Fournier

Laboratoire Hubert Curien UMR5516, CNRS - Université Jean Monnet 18 rue Pr Benoît Lauras, F-42000, St Etienne, France E-mail: corinne.fournier@univ-st-etienne.fr comparing the evaporation rate and droplets velocities obtained by digital holography with those calculated with a simple model of evaporation/condensation. The overall results show that the in line digital holography with "inverse problems" approach is an accurate technique for studying fast evaporation from a Lagrangian point of view.

Keywords Lagrangian tracking · evaporation · digital holography · "inverse problems" approach · rainbow refractometry

\section{Introduction}

The evaporation of droplets is a research area that concerns many practical situations: spray dryers, fuel injection in combustion chambers, atmospheric dispersion, physics of clouds... In a wide majority of cases, droplets vaporize in turbulent flow and a key question is whether or not turbulence influences evaporation (Birouk and Gökalp 2006). As turbulence contributes to disperse the droplets, it is expected that their vaporizing rate is conditioned by the trajectory they follow and the regions of the flow where they accumulate (Reveillon and Demoulin 2007). At the same time, the size evolution caused by the phase-change modifies the forces acting on particles, hence their trajectories, in a complex twoway coupling. To understand this coupling belongs to the challenging and still open questions in fluid mechanics. The best approach to investigate this coupling is to measure the phase-change of the droplet by following it along its trajectory, making a so-called "Lagrangian tracking".

Various techniques can be used for the Lagrangian tracking of solid particles (Toschi and Bodenschatz 2009). They are based on various principles such as 
3D particle tracking velocimetry (PTV) with four cameras (Bourgoin et al 2006), optical imaging with silicon strip detectors (Voth et al 2002), extended laser Doppler anemometry (LDA)(Volk et al 2008), ultrasonic Doppler tracking (Mordant et al 2004) and digital holography (Gopalan et al 2008; Lu et al 2008; Katz and Sheng 2010; Nguyen et al 2011). Compared to the other techniques mentioned, the main advantage of digital holography is that it provides information on size, which is obviously crucial for phase-change studies. It has been shown recently that Digital In-line Holography with an "inverse problem" approach (Soulez et al $2007 a, b)$ is well suited to study the evaporation of droplets in highly turbulent flows, from a Lagrangian point of view (Chareyron et al 2012). These first results were obtained by injecting Freon droplets in a homogeneous quasi isotropic turbulence generated by synthetic jets. Droplets size evolutions were measured along their 3D trajectories from digital holograms recorded with a high speed camera $(3 \mathrm{kHz})$. The "inverse problems" approach selected to process the holograms is known as the optimal approach in terms of signal processing to reconstruct accurately position and shape of parametric objects such as spherical droplets (Gire et al 2008; Fournier et al 2011). It has been found to work well in this complex flow situation and to provide the accuracy on position and diameters which is required for this type of studies. It has also been pointed out that the thermal and/or vapor gradients produced at the droplets interfaces by the evaporation of Freon modify the central part of the droplet fringe pattern and generate a visible wake image on the holograms. These modifications which are not included in the standard parametric model of holograms used in the "inverse problems" method, must be taken into account to keep the high accuracy characterizing this method.

However, some difficulties in injecting the Freon did not permit to keep droplets in the turbulence enough time to measure significant rates of vaporization with the present method and so, to completely evaluate its performances. The objectives of the experiment presented in this paper is to better characterize the holograms disturbances created by the evaporation and to show that droplet diameter tracking can be performed until the end of the evaporation process. As it was difficult to do this in turbulence, experiment is conducted on a jet of mono-dispersed Diethyl Ether droplets falling in air. This fluid has been chosen because it is easier to inject than freon and because it evaporates very fast in ambient conditions, so that the whole vaporizing process can be investigated. The falling velocity of the droplets being weak, the holograms disturbances created by the vapor surrounding the droplets interface are almost spherical and can be analyzed more accurately than with Freon. The results obtained comfort the strategy used in Chareyron et al (2012) to process them and show that the droplets can be tracked using the "inverse problems" method till evaporation ends. An unexpected phenomena, the condensation of humid air at the droplet surface, is revealed by the measurements. The existence of this condensation is validated by two complementary ways: by estimating the evolution of the droplets refractive index from light scattering at rainbow angle and by comparing the data with simulations obtained with a simple model of evaporation/condensation.

The paper is set out as follows. The experimental procedure including the experimental and optical recording setup, is detailed in section 2 . The principle of the "inverse problems" reconstruction is briefly recalled in section 3 . Section 4 presents the results, starting by the holograms disturbances and their processing. The Lagrangian measurements of diameter and velocity obtained with the method thus described follow. The section ends with the refractive index estimation from rainbow measurements and the description of a simple model used to validate the presence of water condensation together with Diethyl Ether evaporation. A brief conclusion summarizes the results and put them into the perspectives of future experiments to be done in turbulent flows.

\section{Description of the experimental procedure}

\subsection{Experimental setup - Injection system}

The falling droplets are generated with a piezoelectric MJT-AT-01 MicroFab Technologies jetting device. This injector, composed of a glass capillary with a $60 \mu \mathrm{m}$ orifice diameter, is operated in a "droplet-on-demand" mode. It delivers mono-dispersed droplets that have approximately the same diameter as that of the glass capillary and an initial velocity $u_{d 0}$ in the range 0.5 $1.1 \mathrm{~ms}^{-1}$. The fluid injected is Diethyl Ether manufactured by Sigma-Aldrich and containing less than $0.1 \%$ residual water. Droplets are released at ambiant temperature and pressure. Their initial diameter and velocity are measured before each run by Phase Doppler Anemometry (PDA), very close to the injector exit, together with air temperature and relative humidity in the room. At the end of vaporization, droplets are so small that they can respond to small air disturbances and doing so, deviate from their vertical trajectory. To avoid it, the end of the droplets jet is slightly sucked through a convergent, as depicted in Fig. 1. The suction velocity $u_{\text {suc }}$ is lower than $0.1 \mathrm{~ms}^{-1}$. 


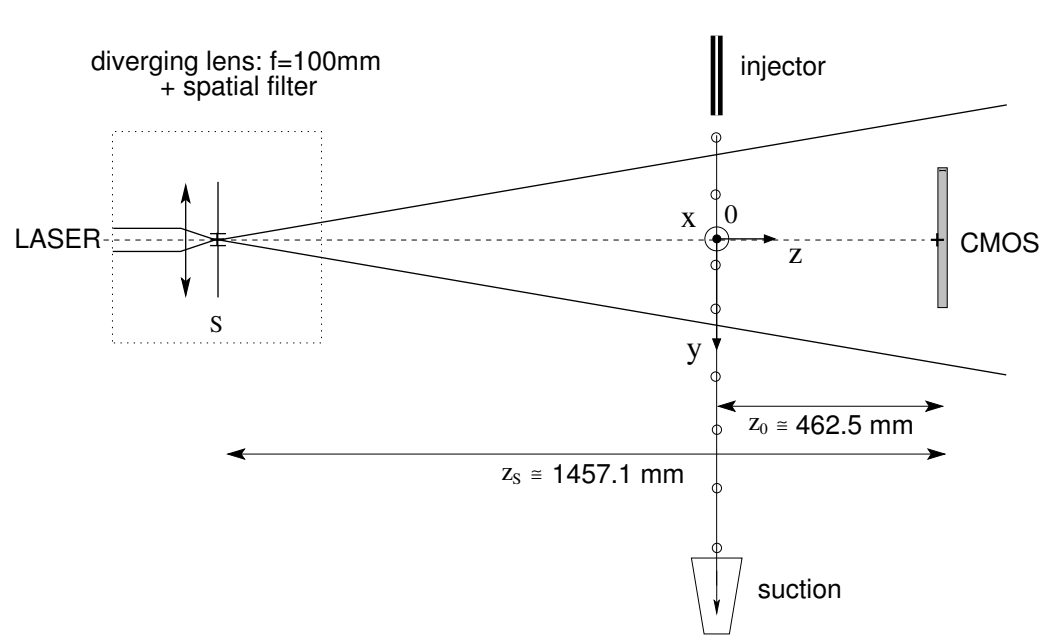

(a)

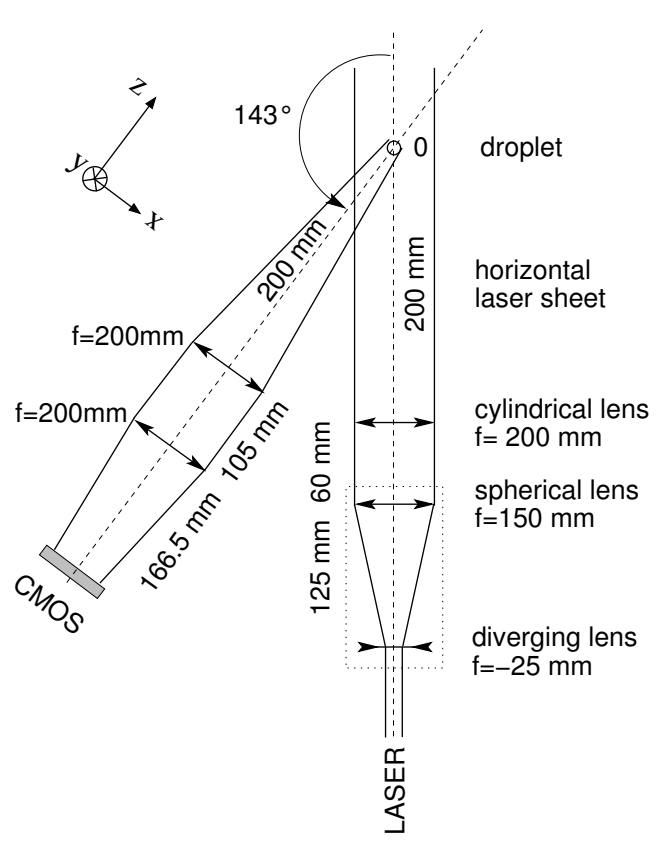

(b)

Fig. 1 (a) Holographic and injection setup. (b) Rainbow measurements setup.

\subsection{Optical setup - Recording parameters - Calibration}

The holograms have been recorded by using the same in line (Gabor) setup as in Chareyron et al (2012). The droplets are illuminated by a laser beam (wavelength $\lambda=532 \mathrm{~nm}$ ) produced by a Nd:YVO4 solid laser Millenia IIs Spectra Physics. The beam is focused onto a spatial filter and expanded by a $100 \mathrm{~mm}$ focal length lens (see Fig. 1), chosen so as to image the entire jet of droplets. The holograms of droplets are recorded at a frequency of $6.2 \mathrm{kHz}$ on the $800 \times 1280$ pixels CMOS sensor of a Phantom V611 camera, pixel size $20 \mu \mathrm{m}$, fill-factor 0.56 . The sensor is positioned at a distance $z_{0}=462.5 \mathrm{~mm}$ from the plane where the droplets are injected. The distance $z_{s}$ between the point source $\mathrm{S}$ (beam waist) and the CMOS sensor is about $1460 \mathrm{~mm}$. The parameters of the setup have been chosen to capture the whole droplet jet. The use of a divergent beam introduces a magnification of the holograms (Vikram and Billet 1988; Lebrun et al 2011) for both object size and reconstruction distance, with a magnification ratio function which is a function of the location $z$ of the object (close to zero). A spherical droplet with coordinates $x_{n}, y_{n}, z_{n}$ and diameter $d_{n}$ is therefore reconstructed as an object located at $x_{n e}=m\left(z_{n}\right) x_{n}, y_{n e}=m\left(z_{n}\right) y_{n}, z_{n e}=m\left(z_{n}\right) z_{n}$ with a diameter $d_{n e}=m\left(z_{n}\right) d_{n}$, where $m\left(z_{n}\right)$ is defined by

$m\left(z_{n}\right)=\frac{z_{s}}{z_{s}+\left(z_{n}-z_{0}\right)}$
Denoting $m_{0}=m(0)$, the magnification at location $z_{n}$ is readily obtained as a function of $m_{0}$ as

$m\left(z_{n}\right)=\frac{m_{0}}{1-\frac{z_{n}}{z_{0}}\left(1-m_{0}\right)}$

Here the location $z_{n}$ of droplets is small compared to $z_{0}$ $\left(\frac{z_{n}}{z_{0}} \ll 1\right)$ and in this case, $m\left(z_{n}\right)$ can be approximated by a linear relationship

$m\left(z_{n}\right)=m_{0}+\frac{z_{n}}{z_{0}} m_{0}\left(1-m_{0}\right)$

The magnification factor has been deduced from calibration by using a linear scale glass reticle (Edmunds Optics, $\sharp 62-252$ ). This reticle is initially placed in the plane $z=0$ of injection and moved apart from this position by increments $\Delta z$ of $1 \mathrm{~mm}$ along $z$, in the range \pm $6 \mathrm{~mm}$. The magnification is obtained by reconstructing the holograms of the reticle located in the successive positions, starting from $z=0$. The reticle grading's on the computed in-focus images allow to calculate $m$ with an uncertainty of 0.005 . The magnification factor decreases linearly with the depth $z_{n}$ following the regression law

$m\left(z_{n}\right)=1.465-0.0015 z_{n}$

with depth $z$ expressed in mm. This law is that used to transform the measured coordinates and diameter $\left(x_{n e}, y_{n e}, z_{n e}, d_{n e}\right)$ into real physical coordinates and diameter $\left(x_{n}, y_{n}, z_{n}, d_{n}\right)$. It also leads to a refined point source position $z_{s}=1457.1 \mathrm{~mm}$. As the droplets' jet 


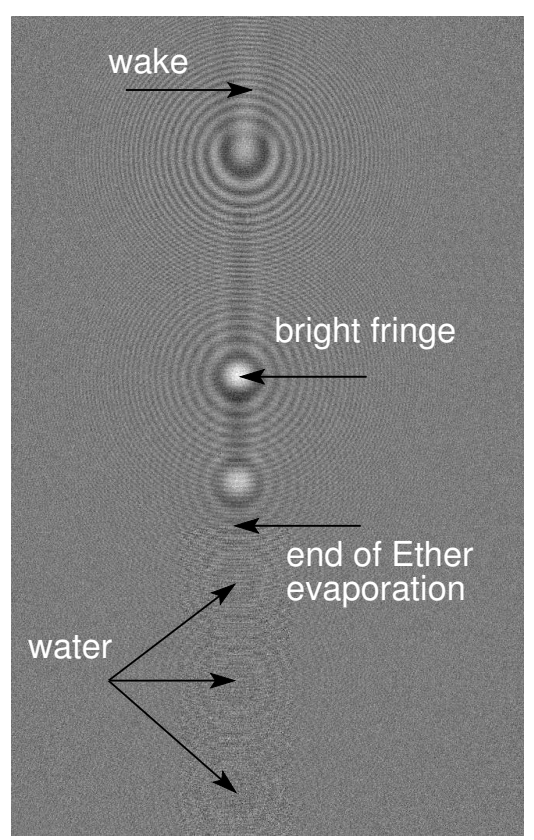

(a)

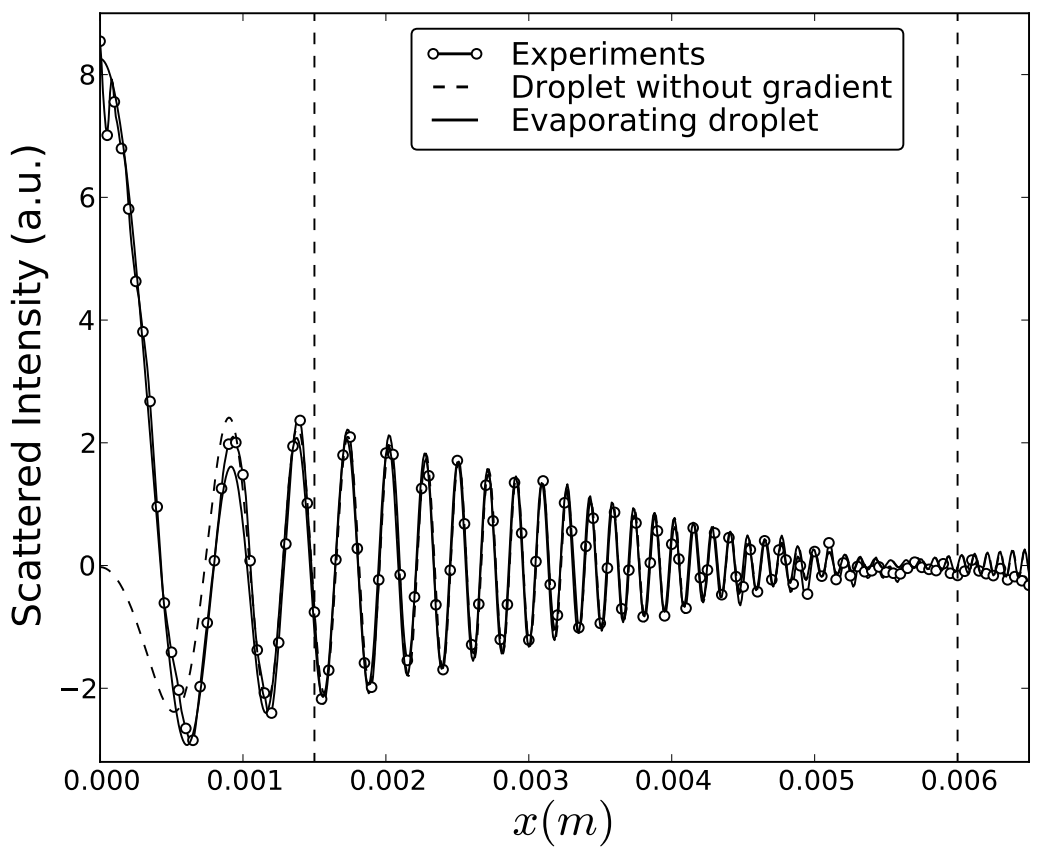

(b)

Fig. 2 (a) Digital hologram of evaporating Diethyl Ether droplets. (b) Radial profile of an experimental hologram compared to synthetic holograms simulated by GLMT, with and without surrounding refractive index gradient (extracted from Fig. 9 in (Méès et al 2013)). In this example, the droplet diameter is $\mathrm{d}=42 \mu \mathrm{m}$ and the distance to the sensor is $z_{0}-z_{n}=360.426 \mathrm{~mm}$.

remains close to the plane $z=0$, the depth correction remains very weak.

\section{$33 \mathrm{D}$ reconstruction of the holograms - Principle of the "inverse problems" algorithm - Tracking}

The classical and most usual way to process the holograms is to simulate numerically the back propagation of light, using for instance Fresnel transform. The 3D image is thus reconstructed in a sample space (plane by plane) and the object parameters (locations and sizes) are determined by locating the in focus plane of each object. The limitations encountered in doing so have been well identified (Gire et al 2008). The most restrictive are the limited depth accuracy and the limited field of view due to border effects.

Here, the image processing of the holograms is performed using an "inverse problems" approach proposed by Soulez et al $(2007 a, b)$. This hologram processing amounts to a pattern recognition. The synthetic hologram (pattern) formed in the far-field by a spherical droplet with given diameter $d_{k}$ and location $x_{k}, y_{k}, z_{k}$ depends only on these four parameters (Tyler and Thompson 1976) and has a closed-form expression (direct problem), considering the spherical droplet as an opaque circular disk. The "inverse problems" approach consists in finding iteratively (i.e. particle per particle) within a 4D search space, the set of parameters $x_{k}, y_{k}, z_{k}, d_{k}$ producing the synthetic hologram that best matches each individual droplet hologram on the image. This is possible because the concentration in droplets is low in our experiment (i.e., satisfying Royer criterion (Royer 1974)), so that the hologram can be approximated by the sum of the individual holograms produced by each droplet. Hologram inversion is performed iteratively. Once the set of parameters matching an individual droplet hologram is found, the corresponding synthetic hologram is subtracted from the image (cleaning step) and the next droplet is searched. In contrast to the classical approaches, these computed holograms intrinsically take into account truncation and low spatial resolution of the sensor which are significant sources of error and low accuracy measurements. As shown in Chareyron et al (2012), Soulez et al (2007b), the inverse approach allows higher accuracy measurements of both sizes and (transverse and depth) positions of droplets, and can significantly expand the field of view outside of the sensor area.

In the present case, the use of a standard back propagation reconstruction process would lead to a spa- 
tial resolution of about $15 \mu \mathrm{m}$ (Garcia-Sucerquia et al 2006), based on a two-points Rayleigh criteria. When using the 'inverse problems' approach, the spatial resolution and the lowest size measurement achievable cannot be easily estimated from theoretical considerations. In practice, these limits mainly depends on the squared signal to noise ratio and the signal quantification (Fournier et al 2010). There is essentially two ways to estimated these limits. It can be done experimentally, using calibrated objects when possible. In the experimental conditions here considered, it has been done using simulations. Diffraction patterns have been computed for decreasing droplet diameters, a Gaussian white noise similar to the one observed experimentally has been added and inversed using the inverse problems algorithm. As a result, the smallest measurable droplet diameter is found to be of the order of $8 \mu \mathrm{m}$ and for greater or equal droplet diameter, the accuracy remains smallest than $0.5 \mu \mathrm{m}$.

The processing of each holograms gives the positions and diameter of droplets at various successive instant of the film. The 3D trajectory and the diameter evolution along each droplet trajectory is then deduced via a tracking method. The distance between droplets over their diameter $\frac{L}{d}$ being $>100$, tracking has been achieved by using a simple 3D nearest-neighbor criterion. This also means that droplets evaporate without interacting.

\section{Results}

\subsection{Holograms of evaporating droplets}

Fig. 2 (a) shows an hologram of the droplet jet after background removal, as described in Seifi et al (2013). It confirms the trends observed in the case of freon droplets (Chareyron et al 2012). When evaporation takes place (upper part of the figure), the droplet holograms are modified. The central fringe of the holograms is abnormally bright compared to what is expected with a non-evaporating droplet. In addition, a wake image is visible behind the holograms. Both modifications are attributed to the deflection of the light by the refractive index gradient in the thermal - vapor concentration boundary layers and wakes developing around the droplet. This assumption is supported by the fact that the wake image is aligned with the relative motion of the air around the droplet. Here, the image wake is vertical, opposed to the falling velocity, while for freon droplet it was aligned with the Lagrangian turbulent relative velocities seen by the droplets. The proof that index gradient are at the origin of the brightness excess have been recently provided by rigorous electro- magnetic scattering calculations (Méès et al 2013). As the falling velocity of Diethyl Ether droplet is weak (see 4.2), the thermal-concentration layers around the droplet can be considered as almost spherical and can be modeled by multi-layered spheres of various refractive index decaying exponentially, in agreement with the measurements of Toker and Stricker (1996, 1998). Simulations using the Generalized Lorenz-Mie Theory (GLMT) on this multi-layered sphere are found to well reproduced the brightness excess of the real holograms (see Fig. 2 (b)). This unusual central fringe brightness is the most problematic for the "inverse problems" approach, because it is not described by the hologram formation model of droplets. To get rid of this problem, a weighted mask method has been used in Chareyron et al (2012) to exclude the central part of the hologram from the reconstruction process. This is also the technique which was adopted to obtain the data presented in the next subsection. As shown in Méès et al (2013), Seifi et al (2013), the refractive index gradient affects the three central fringes of the holograms. The size of the mask is hence chosen to exclude these fringes. The same mask size can be applied for all the droplets patterns, as the variation of $z_{n}$ remains weak compared to $z_{0}$ (small variations of the first rings diameters). This is illustrated by Fig.3 of Seifi et al (2013), where the steps for creating a mask with an optimal size are detailed. The efficiency of the excluding mask for finding the model parameters that best fit the modified holograms of droplets has been clearly demonstrated in the same reference. A more satisfactory approach for the future would be to develop a hologram formation model which takes into account the surrounding medium refractive index gradient. GLMT could be very helpful to validate such a model. The modifications described above vanish in the holograms of the lower part of the figure. As will be discussed thereafter, this occurs when all the Diethyl Ether is evaporated and droplets are only composed of residual water. Note that the corresponding holograms are less contrasted because the droplets are very small.

4.2 Lagrangian time evolution of the droplets diameter and velocity

The reconstruction method previously described enables to track the droplets till they fully evaporate. This is illustrated in Fig. 3 (a) that shows the Lagrangian time evolution of the diameter square of two Diethyl Ether droplets (initial diameters $d_{0}=52.5 \mu \mathrm{m}$ and $55.5 \mu \mathrm{m})$ at different ambient temperatures and relative humidities. On these examples, 500 to 600 holograms have been processed to measure the diameter 


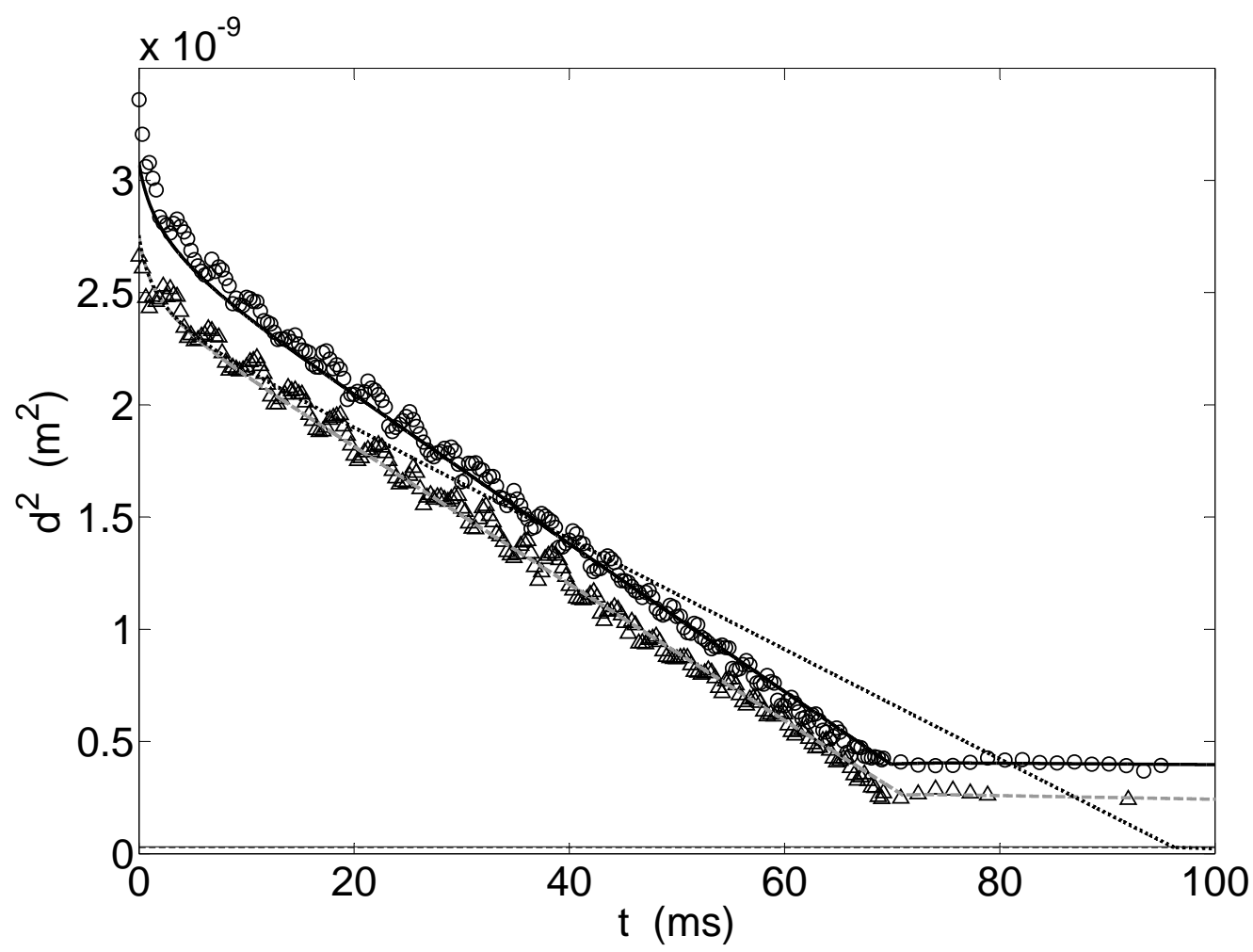

(a)

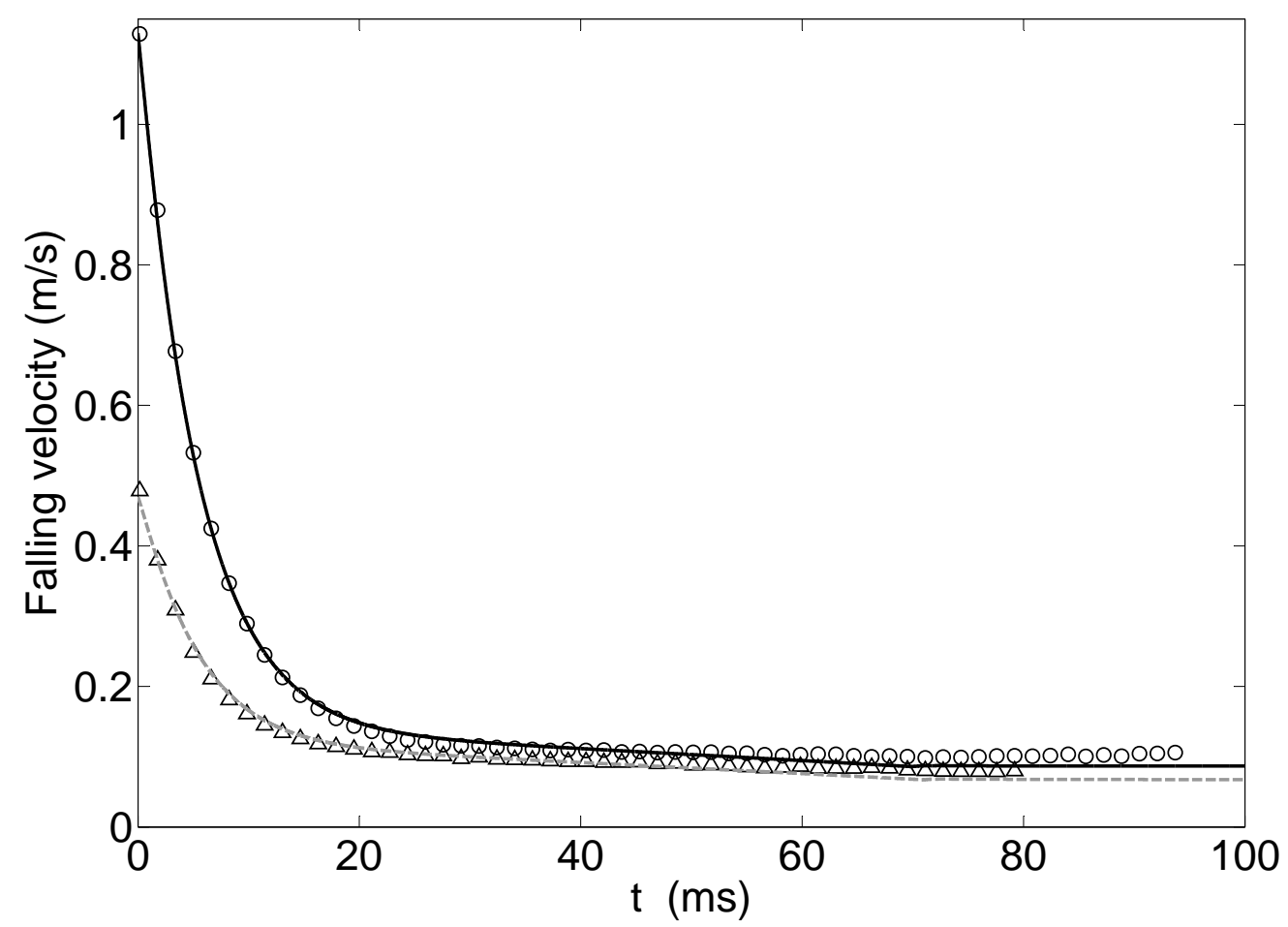

(b)

Fig. 3 (a) Diameter square versus time. $(\triangle)$ measurement and $(--)$ simulation for $T^{\infty}=25^{\circ} \mathrm{C}, R_{h}=0.36, d_{0}=52.5$ $\mu \mathrm{m}, u_{d 0}=0.47 \mathrm{~ms}^{-1}, u_{s u c}=0.060 \mathrm{~ms}^{-1} ;(\ldots)$ simulation for the same parameters but for $R_{h}=0$; (o) measurement and simulation (-) for $T^{\infty}=21.5^{\circ} \mathrm{C}, R_{h}=0.70, d_{0}=55.5 \mu \mathrm{m}, u_{d 0}=1.13 \mathrm{~ms}^{-1}, u_{s u c}=0.075 \mathrm{~ms}^{-1}$. Horizontal line on bottom: plateau corresponding to the $0.1 \%$ water initially contained in the droplet. (b) Fall velocity versus time, same legend notations. 
along the whole trajectory of the droplets. Whatever the conditions, the Diethyl Ether evaporate within a very short time. This means that Diethyl Ether is a good candidate to replace the freon for experiments in turbulent flows. From $10 \mathrm{~ms}, d^{2}$ on decreases almost linearly with time, following the $d^{2}$ law which characterizes a quasi-steady evaporation (Law 1982). This linear decrease is accompanied by $\pm 0.5-0.6 \mu \mathrm{m}$ oscillations of the diameter whose origin is still unknown. They may arise either from the algorithm used to process the hologram or from unsuspected physical phenomena linked to evaporation or droplet dynamics. Past $70 \mathrm{~ms}$, the droplet diameter reaches systematically a plateau, meaning that the evaporation is stopped. This plateau can be explained assuming that all the Diethyl Ether is then evaporated and the droplet is only composed of residual water which evaporates much more slowly. However, the Diethyl Ether used here contains less than $0.1 \%$ of water (provided by manufacturer and checked experimentally), while the volume ratio, deduced from the initial droplet diameter and the diameter at plateau leads to an amount of about $4 \%$. A way to explain this difference is to assume that the fast evaporation of the Diethyl Ether cools the humid air around the droplet and causes its condensation at the surface. The existence of condensation was reported by Law et al (1987) for Alcohol droplet vaporizing in humid air. They showed that the water vapour condensed at the surface of the droplet and that the condensation heat release enhanced the vaporization of Alcohol. As the Diethyl Ether is much more volatile, the same process is likely to take place. The fact that the diameter $d_{w}$ of the plateau is increasing with the relative humidity of the air $\left(d_{w}=15 \mu \mathrm{m}\right.$ for $R_{h}=0.36, d_{w}=19 \mu \mathrm{m}$ for $\left.R_{h}=0.70\right)$ is consistent with this scenario. To check that condensation takes place, the evolution of the droplets refractive index has been estimated from light scattering measurements at rainbow angle (subsection 4.3). These measurements have been completed by simulations based on a simple evaporation model including the condensation effect (subsection 4.4). The Lagrangian fall velocities of the two droplets are displayed in Fig. 3(b). In both cases, the velocity tends asymptotically to a constant value which corresponds to the suction velocity of the convergent used to stabilize the jet of droplets. The suction velocities are lower than $0.1 \mathrm{~m} / \mathrm{s}$, so that droplets are in quasi "free" falling conditions.
4.3 Evolution of the droplets refractive index -

Measurements at rainbow angles

Light scattering by a spherical particle at rainbow angle is known to be sensitive to the particle refractive index (van de Hulst 1957). Interferometric measurement at this particular angle can provide very accurate size and refractive index measurements (Han et al 1998, 2001), as long as the particle remains perfectly spherical (Tropea 2011; van Beeck and Riethmuller 1996), which is a reasonable assumption for the liquid droplets of a few tens microns falling in still air, considered in this paper. However, building a highly accurate droplet size and refractive index measurement based on rainbow pattern is a very difficult task, because rainbow pattern is influenced by various parameters. It is very sensitive to the droplet location and accurate measurements require a perfect knowledge of the scattering angle $\theta$. It is also sensitive to the presence of refractive index gradients inside the droplet. Building such a very accurate refractive index measurement is then out of the scope of this paper. Our objective is to estimate the droplets' refractive index as a function of their distance to the nozzle, in order to assess the presence of water condensation together with ether evaporation. Thus, a second experimental setup has been build to record the droplet rainbow patterns. As shown in Fig. 1(b), the same Nd:YVO4 laser as for holographic measurements is used to illuminate the droplets chain. A couple of lenses (one spherical and one cylindrical) is used to generate a horizontal laser sheet, illuminating one droplet at a time. The same CMOS sensor is used to record the scattering intensity in proximity of the rainbow angle. The angle $\theta$ between the laser sheet, the droplet and the center of the sensor is about $143^{\circ}$.

Instead of directly recording the rainbow pattern, two spherical lenses are used to realize an out of focus image of the droplet using the same principle as for Interferometric Laser Imaging Droplet Sizing (ILIDS) (Ragucci et al 1990; Glover et al 1995) also known as Interferometric Particle Imaging (IPI), but at rainbow angle. The droplet image is thus a circular pattern containing the rainbow fringes as shown in Fig. 4. The main advantage of this out-of-focus configuration is to better control the location of the droplets, as any displacement of the jet parallel to the sensor leads to a displacement of the circular pattern on the image and any displacement perpendicular to the sensor leads to a reduction or an enlargement of the circle diameter. Circular patterns which are not centered on the image or showing larger or smaller diameter are thus excluded, ensuring measurements at a nearly constant angle $\theta$ (the tolerance is set to 40 pixel in both circle position and diameter, cor- 


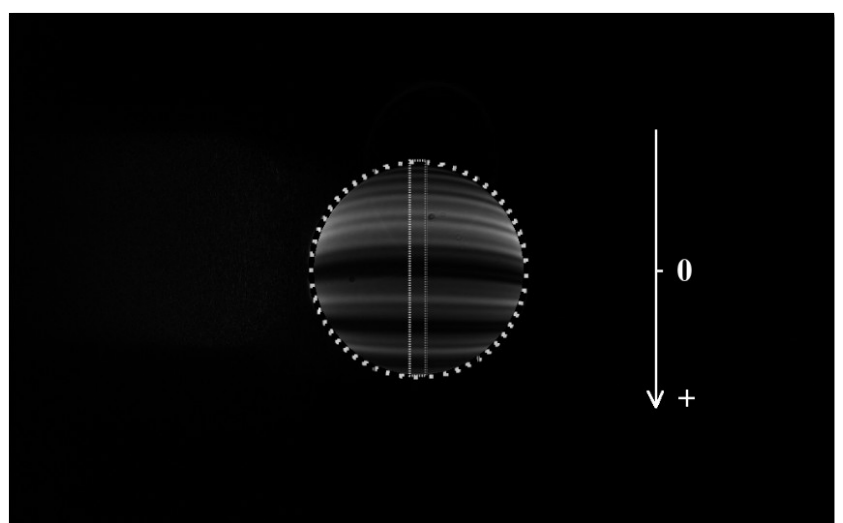

Fig. 4 Interferometric droplet image at rainbow angle. The rainbow pattern is extracted and plotted versus pixel number by adopting the reference axis in white.

responding to angle variation lower than 0.25 degree). In addition, the out of focus distance (distance between the sensor and the second lens) can be adjusted to increase the resolution (larger image size) or increase the recorded intensity (smaller image size).

To determine the recording angle accurately and to take into account the signal distorsions due to geometrical aberrations of the optics, a calibration procedure is required. To do so, water droplets (refractive index $\left.n_{w}=1.333\right)$ are injected, and PDA measurement provide an average diameter of $65.8 \mu \mathrm{m}$ with a standard deviation of $0.21 \mu \mathrm{m}$. Fig. 5 shows rainbow pattern extracted from 4 different droplet interferometric images (average of 20 pixel columns in the rectangle of Fig. 4). Rainbow pattern is composed of a low frequency component (the Airy pattern (Airy 1838)), which corresponds to optical rays reflected once inside the droplet and a high frequency component, called the ripple structure, resulting from interferences between the Airy pattern and rays directly reflected by the droplet. Airy pattern is sensitive to both refractive index and droplet diameter. As a rule of thumb, any change in refractive index leads to an angular translation of the pattern, when the distances between the bows (the main bow and two supernumerary bows are visible in Fig. 5) depends on the droplet size. In Fig. 5, the 4 different droplets show similar Airy patterns (low frequencies), as it should be for droplet diameters and refractive index very close to each other. However, the ripple structure, which is extremely sensitive to droplet diameter (Han et al 1998), differ from one droplet to another, due to the small variations in droplet diameter (in the order of $200 \mathrm{~nm}$, measured by PDA).

It is then suitable to perform the angular calibration of the experiment based on the Airy pattern only. The experimental rainbow patterns are thus filtered in order to remove the ripple structure (low-pass filter). These

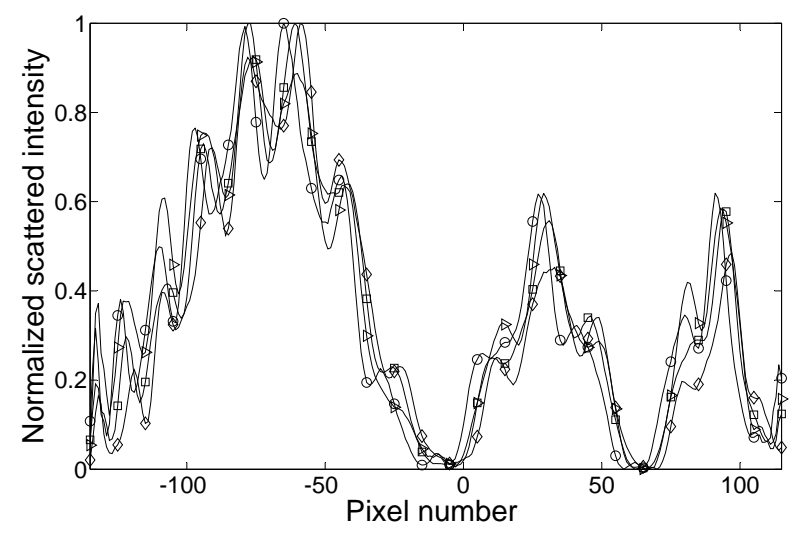

Fig. 5 Rainbow patterns of four different water droplets. The droplet diameters are close to $65.8 \mu \mathrm{m}$. The droplets show the same Airy pattern (low frequency components) but different ripple structures (high frequency component) which are very sensitive to small variation of the diameter, in the order of $200 \mathrm{~nm}$ in the present case.

filtered signals (Fig. 6(a)) are then compared to a rainbow pattern (Fig. 6(b)), computed by using Lorenz-Mie Theory (LMT) (Bohren and Huffman 1983) and also filtered to remove the ripple structure. The droplet diameter used for computation is the average diameter measured by PDA $(65.8 \mu \mathrm{m})$ and the refractive index of water is assumed to be $n_{w}=1.333$. A correspondence between pixel number and scattering angle is then found by associating the pixel coordinates of characteristic points of the experimental curves (maximum, minimum and inflection points of the bows) and the angle of these points in the computed pattern. These points coordinates are plotted in Fig. 7 (crosses) as well as a cubic interpolation to be used as a calibration curve.

Diethyl Ether droplets are then injected in the same conditions as for DIH measurements and droplet rainbow patterns are recorded for various distances from the nozzle exit, and plotted as a function of scattering angle using the calibration curve. Note that rainbow patterns from different droplets are recorded for each distance from the nozzle. Measurements are not done along the same droplet trajectory as for digital holography. For each pattern, a best fit is searched with Lorenz-Mie computations, leading to refractive index and droplet size estimation. The calibration has been done using filtered signal (Airy pattern). For Ether droplets, the rainbows patterns are not filtered, since the droplet size is decreasing, the ripple and Airy frequencies become too close to be separated. Fig. 8 shows examples of droplet rainbow pattern compared to the best fit issued from LMT computations. 
(a)
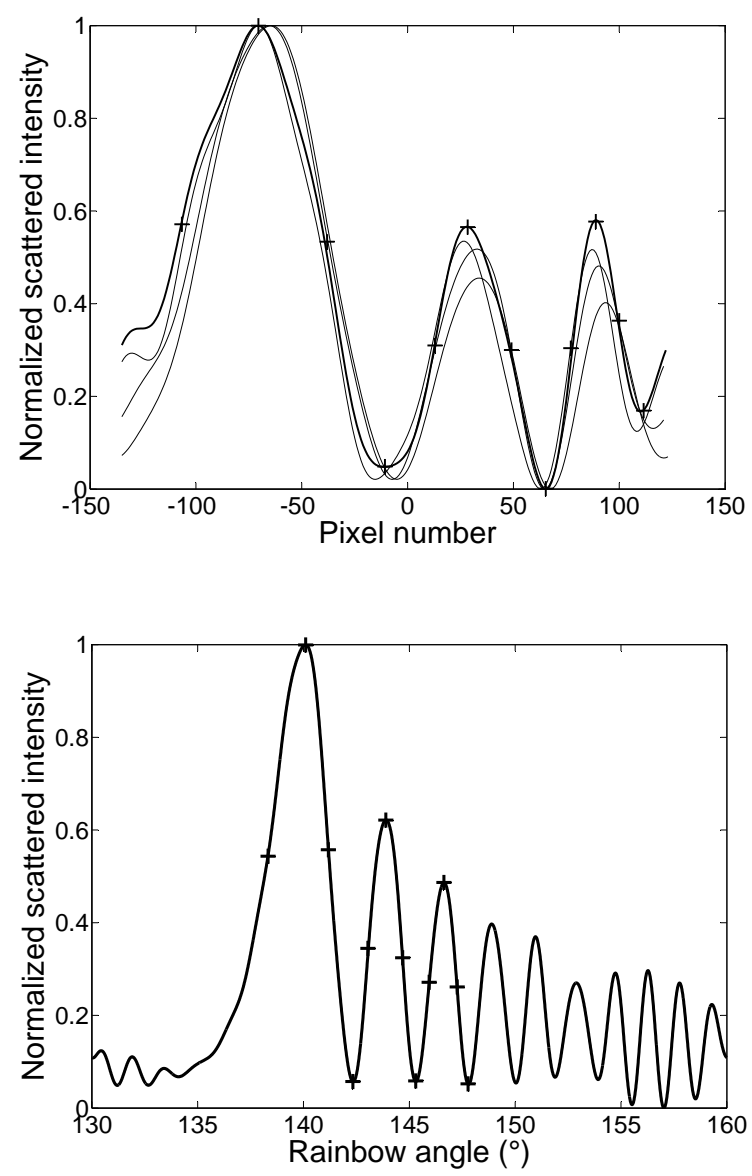

(b)

Fig. 6 (a): Patterns of Fig. 5 after filtering; the correspondence between pixel number and scattering angle for the pattern in bold is achieved with the characteristics points represented by the crosses. (b) Filtered theoretical pattern calculated with LMT for a $65.8 \mu \mathrm{m}$ diameter water droplet.

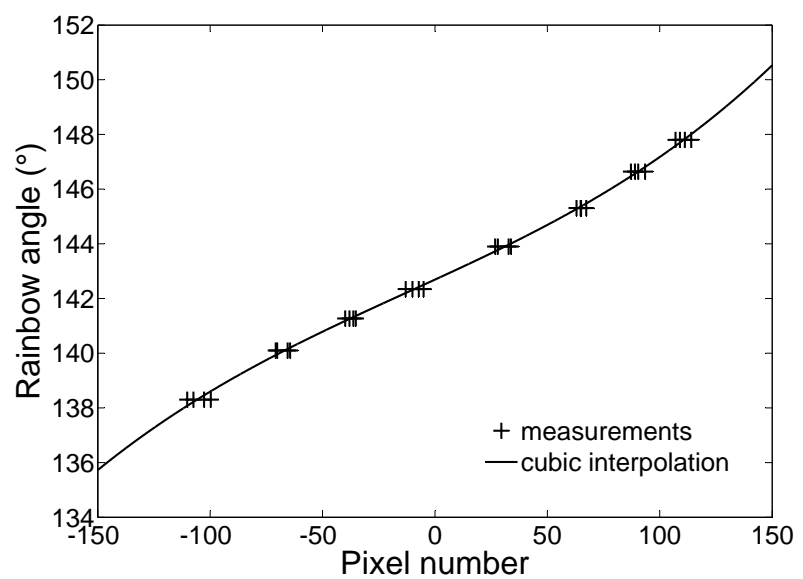

Fig. 7 Calibration curve: pixel number - Rainbow angle in degrees.

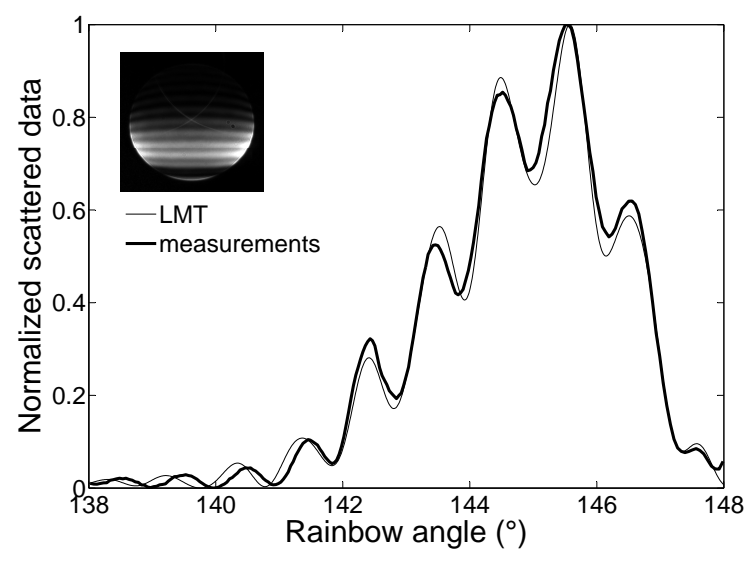

(a)

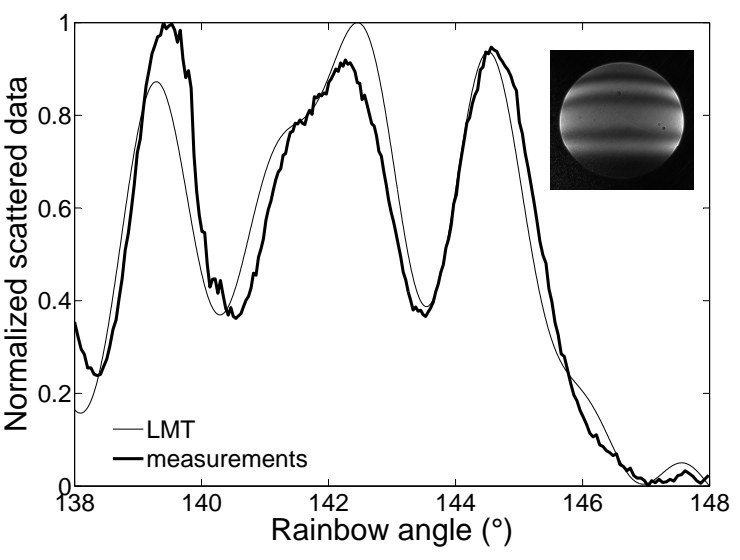

(b)

Fig. 8 (a): The best fit between LMT and measurements is obtained for $\mathrm{n}=1.3725$ and $\mathrm{d}=49.3428 \mu \mathrm{m}$; the droplet is located at $\mathrm{Y}=6 \mathrm{~mm}$ from the injector (see Fig.9). (b): The best fit between LMT and measurements is obtained for $\mathrm{n}=1.3375$ and $\mathrm{d}=19.1070 \mu \mathrm{m}$; the droplet is located at $\mathrm{Y}=16 \mathrm{~mm}$ from the injector.

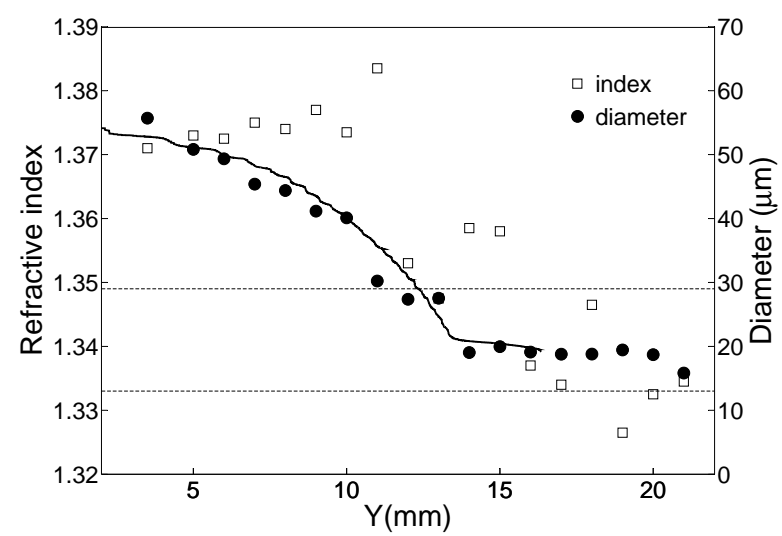

Fig. 9 Refractive index and diameter of a droplet measured at rainbow angle as a function of its distance from the injector. - diameter evolution of a droplet of the same size as measured at a different time by holography. 
Fig. 9 shows the estimation of the refractive index as a function of the distance between the droplet and the nozzle. The refractive index values are of the order of 1.375 for the shortest distances, that is significantly greater than value generally admitted for liquid Diethyl Ether, which is about 1.35. This over-estimation is due to the presence of a refractive index gradient (temperature and/or composition gradient due to evaporation) inside the droplet as shown in Saengkaew et al (2007). At larger distances from the nozzle (between 11 and 15 $\mathrm{mm}$ ), the measured refractive index decreases fast and not regularly. For a nozzle distance greater than $15 \mathrm{~mm}$, the measured refractive index is clearly lower with an average value of 1.335 . The rainbow measurements thus confirm the assumption that droplet are composed of pure water when their diameter reaches the plateau. In addition to the refractive index, the analysis of rainbow patterns provides a droplet diameter estimation, which is in very good agreement with DIH size measurement as shown in Fig. 9.

4.4 Comparison of the experimental data with a simple model of evaporation/condensation

Taking advantage of the rather simple configuration studied in this paper (falling droplets in quasi-still air), the evaporation of the droplets has been simulated by solving the coupled system of equations for the motion and interfacial transfer between the droplet and its surroundings, as described in Abramzon and Sirignano (1989), Guella et al (2008). In our situation the main forces acting on the droplets reduce to gravity and the drag force, thus the equation of motion reads

$\frac{d \mathbf{u}_{d}}{d t}=\left(1-\frac{1}{\gamma}\right) \mathbf{g}+\frac{3 C_{D}\left(R e_{d}\right)}{4 d \gamma}\left|\mathbf{u}-\mathbf{u}_{d}\right|\left(\mathbf{u}-\mathbf{u}_{d}\right)$

where $\gamma$ is the ratio of densities $\rho_{d} / \rho_{g}, \mathbf{u}_{d}$ the droplet velocity , $\mathbf{u}$ the gas velocity and $R e_{d}$ the Reynolds number based on the droplet diameter $d$ and the relative velocity $\mathbf{u}_{r}=\mathbf{u}-\mathbf{u}_{d}$. The gas velocity is for simplicity taken constant and equal to the suction velocity $u_{\text {suc }}$ near the entrance of the convergent. The Diethyl Ether droplets have a Reynolds number typically in the range $0 \leq R e_{d} \leq 10$ and can be considered as non-interacting during evaporation (see section 3 ). So, the drag coefficient has been estimated by the correlation proposed by Clift for this case (Clift et al 1978)

$C_{D}\left(R e_{d}\right)=\frac{24}{R e_{d}}\left(1+\beta R e_{d}^{\alpha}\right)$

where $\beta=0.1935$ and $\alpha=0.6305$. The vaporizing rate of the Diethyl Ether and the heat transferred into the droplet are expressed on the base of the double film theory (Bird et al 1960). According to this theory and its simplifying assumptions the vaporization rate is given by

$$
\begin{array}{r}
\dot{m}_{d e}=\frac{d m_{d e}}{d t}=\pi \rho_{g} d D_{d e} S h_{F} \log \left(1+B_{M}\right) ; \\
B_{M}=\frac{Y_{d e}^{s}-Y_{d e}^{\infty}}{1-Y_{d e}^{s}}
\end{array}
$$

in which $D_{d e}$ denotes the diffusion coefficient of the Diethyl Ether in the gas film, $B_{M}$ and $S h_{F}$ the Spalding and the Sherwood numbers for the vapor concentration. $Y_{d e}^{s}$ and $Y_{d e}^{\infty}$ are the mass fractions of vapor at the droplet surface and at infinity. For the sake of simplicity, $Y_{d e}^{\infty}$ is set to zero, while $Y_{d e}^{s}$ is evaluated assuming, as usual, the equilibrium liquid/vapour at the interface (quasi stationary approach). Hence

$Y_{d e}^{s}=\frac{P_{d e}^{s a t}\left(T^{s}\right)}{P_{d e}^{s a t}\left(T^{s}\right)+\left(P-P_{d e}^{s a t}\left(T^{s}\right)\right) \frac{M_{g}}{M_{d e}}}$

The ratio appearing in the denominator is the ratio of the gas molar mass to the Diethyl Ether vapor one, $P$ the atmospheric pressure. $P_{d e}^{s a t}\left(T^{s}\right)$ is the Diethyl Ether vapor pressure at droplet surface temperature $\left(T^{s}\right)$. It can be calculated by using the Clausius-Clapeyron equation. Here it is obtained from the correlation provided by the Cheric Data Base for this substance:

$$
\begin{array}{r}
P_{d e}^{s a t}\left(T^{s}\right)=1000 \exp \left(-12.43790 \log \left(T^{s}\right)-\frac{6340.514}{T^{s}}\right. \\
\left.+1.412918 \times 10^{-05} T^{s 2}\right)
\end{array}
$$

$S h_{F}$ is determined by

$S h_{F}=2+\frac{S h_{0}-2}{F_{M}\left(B_{M}\right)}$

$S h_{0}$ is the Sherwood number for a non vaporizing sphere and $F_{M}$ a factor that accounts for the blowing of the concentration film caused by the Stefan flow. Assuming to simplify that the heat conduction is infinite within the droplet, the heat transferred to the droplet can be expressed as

$$
\begin{array}{r}
\rho_{d} V_{d} C_{p d} \frac{d T^{s}}{d t}=\frac{S_{d} \lambda_{g}}{d} N u_{F} \frac{\log \left(1+B_{T}\right)}{B_{T}}\left(T^{\infty}-T^{s}\right) \\
-L_{v d e}\left(T^{s}\right) \dot{m}_{d e}
\end{array}
$$

where $V_{d}, S_{d}$ denote the volume and the surface of the droplet, $C_{p d}$ its specific heat, $\lambda_{g}$ the heat conductivity of the gas in the film, $B_{T}$ the Spalding and $N u_{F}$ the 
Nusselt numbers for the temperature, and $L_{v d e}$ the latent heat of vaporization of Diethyl Ether. The value for $L_{v d e}$ is taken from the Cheric Data Base. $B_{T}$ and $B_{M}$ are linked by the relationship

$$
\begin{aligned}
\log \left(1+B_{T}\right) & =\frac{P_{r g}}{S_{c g}} \frac{S h_{F}}{N u_{F}} \log \left(1+B_{M}\right) ; \\
P_{r g} & =\frac{\mu_{g} C_{p g}}{\lambda_{g}} ; \quad S_{c g}=\frac{\mu_{g}}{D_{d e} \rho_{g}}
\end{aligned}
$$

$P_{r g}$ is the Prandt number, $S_{c g}$ the Schmidt number of the gas. By analogy with the Sherwood number, $N u_{F}$ can be expressed as

$N u_{F}=2+\frac{N u_{0}-2}{F_{T}\left(B_{T}\right)}$

with $N u_{0}$ the Nusselt number for a non vaporizing sphere and $F_{T}$ a factor that accounts for the blowing of the temperature film caused by the Stefan flow. According to Abramzon and Sirignano (1989) $F_{M}$ and $F_{T}$ can be approximated as $F\left(B_{M}\right)$ and $F\left(B_{T}\right)$ respectively, $F$ being the universal function

$F(B)=(1+B)^{0.7} \frac{\log (1+B)}{B}$

The Reynolds numbers of the droplets in our experiment being low, typically $<10$, the Clift correlations (Clift et al 1978) have been preferred to the well-known Ranz-Marshall (Ranz and Marshall 1952) or Frössling (Frössling 1938) correlations, to estimate $N u_{0}$ and $S h_{0}$ (Abramzon and Sirignano 1989). They are written in the following form

$$
\begin{aligned}
& S h_{0}=1+\left(1+R e_{d} S_{c g}\right)^{\frac{1}{3}} f\left(R e_{d}\right) \\
& N u_{0}=1+\left(1+R e_{d} P_{r g}\right)^{\frac{1}{3}} f\left(R e_{d}\right)
\end{aligned}
$$

where $f\left(R e_{d}\right)=1$ for $R e_{d} \leq 1$ and $f\left(R e_{d}\right)=R e_{d}^{0.077}$ for $R e_{d} \leq 400$. As proposed in Hubbard et al (1975), Yuen and Chen (1976), the thermophysical average properties in the gas film around the droplet are calculated at a temperature and a vapor mass fraction of reference, based on the so-called 1/3 law:

$T^{r}=\frac{2}{3} T^{s}+\frac{1}{3} T^{\infty} ; \quad Y_{d e}^{r}=\frac{2}{3} Y_{d e}^{s} ;$

The gas in the film around the droplet is considered as a mixture of the humid air in the room and the vapor of Diethyl Ether. From the relative humidity $R h^{\infty}$ and temperature $T^{\infty}$ in the room, the thermophysical and transport properties of humid air at the reference temperature are determined using the correlations proposed by Tsilingiris (2008). The density and specific heat of the gas mixture in equations $(7,12)$ are evaluated as

$$
\frac{1}{\rho_{g}}=\frac{Y_{d e}^{r}}{\rho_{d e}^{r}}+\frac{1-Y_{d e}^{r}}{\rho_{h a}^{r}} ; \quad C_{p g}=Y_{d e}^{r} C_{p d e}^{r}+\left(1-Y_{d e}^{r}\right) C_{p h a}^{r}
$$

The heat conductivity $\lambda_{g}$ and viscosity $\mu_{g}$ of the gas mixture in equations $(11,12)$ are calculated by using the formula of Wassiljewa (1904) and Wilke (1950), respectively. The Reynolds number $R e_{d}$ used in the equations is the Reynolds number estimated in the reference conditions:

$R e_{d}=\frac{\rho_{h a}^{\infty}\left(u_{d}-u_{s u c}\right) d}{\mu_{g}^{r}}$

Finally the diffusivity of the vapor of Diethy Ether in air is determined by the Chapman-Enskog first-order equation. For the liquid phase, the density $\rho_{d}$ and viscosity $\mu_{d}$ are taken from Meng et al (2008) while the specific heat $C_{p d}$ from Green and Perry (2008). The system of equations has been solved by using the solver of differential equations 'ode113' Matlab. The initial conditions for the calculation are the initial diameter $d_{0}$, velocity $u_{d 0}$, and temperature $T_{0}^{s}$ of the droplet, the temperature $T^{\infty}$ and the relative humidity $R h^{\infty}$ in the room. The injector being at the ambient temperature, $T_{0}^{s}$ is assumed to be equal to $T^{\infty}$. The initial droplet velocity is measured using PDA, as close as possible to the injector exit. The system of equations is solved iteratively as it is usually done in this kind of modeling (Abramzon and Sirignano 1989). $T^{s}$ is used at each step to calculate $T^{r}, Y_{d e}^{r}$, the composition and physical properties of the gas mixture around the droplet, and the liquid phase properties. Then $B_{T}$ is inferred from $B_{M}$ through equations $(12,13,14,15)$ and the values of $u_{d}, \dot{m}_{d e}, T^{s}$ are obtained for the next step. The droplet diameter $d$ is easily determined from the vaporizing rate. The time evolution of $d^{2}$ obtained by the simulation for $T^{\infty}=25^{\circ} \mathrm{C}, R_{h}=0.36$ are compared to the holographic measurements in Fig. 3(a). Without taking into account the condensation of the humid air, the model underestimates the evaporation rate and the evaporation totally ends at $t=90 \mathrm{~ms}$, against $t=70$ $\mathrm{ms}$ for the data. The plateau in the model corresponds to the residual water initially contained in the Diethyl Ether $(\sim 0.1 \%)$ and so, is much lower than the real one. To check that the condensation of the humid air at the droplet surface can explain the deviation between the model and the experiments, an attempt to include this condensation effect into the model has been made. Noting $\rho_{w}$ the density and $\dot{m}_{w}$ the condensation rate of water, the time evolution of the droplet volume and its 
water volume can be expressed by

$\frac{d V_{d}}{d t}=-\frac{\dot{m}_{d e}}{\rho_{d e}}-\frac{\dot{m}_{w}}{\rho_{w}} ; \quad \frac{d V_{w}}{d t}=-\frac{\dot{m}_{w}}{\rho_{w}}$

With the convention of sign adopted, $\dot{m}_{d e}$ is positive while $\dot{m}_{w}$ is negative. The condensation rate is calculated from an equation similar to that used for evaporation:

$$
\begin{array}{r}
\dot{m}_{w}=\frac{d m_{w}}{d t}=\pi \rho_{h a} d D_{w} S h_{0 w} \log \left(1+B_{M w}\right) ; \\
B_{M w}=\frac{Y_{w}^{s}-Y_{w}^{\infty}}{1-Y_{w}^{s}}
\end{array}
$$

where $D_{w}$ and $S h_{0 w}$ denote the diffusion coefficient and the Sherwood number of water vapor, respectively. $S h_{0 w}$ is given by equation (15) in which $S_{c g}$ is replaced by $S_{c w}$, the Schmidt number of water vapor. $Y_{w s}^{s}$ and $Y_{w}^{\infty}$, the mass fractions of water vapor at the surface of the drop and at infinite are determined by

$$
\begin{array}{r}
Y_{w}^{s}=\frac{P_{w}^{s a t}\left(T^{s}\right)}{P_{w}^{s a t}\left(T^{s}\right)+\left(P-P_{w}^{s a t}\left(T^{s}\right)\right) \frac{M_{d a}}{M_{w}}} \\
Y_{w}^{\infty}=\frac{R h^{\infty} P_{w}^{s a t}\left(T^{\infty}\right)}{R h^{\infty} P_{w}^{s a t}\left(T^{\infty}\right)+\left(P-R h^{\infty} P_{w}^{s a t}\left(T^{\infty}\right)\right) \frac{M_{d a}}{M_{w}}}
\end{array}
$$

$P_{w}^{s a t}\left(T^{s}\right)$ is obtained from the usual correlation for water vapor:

$$
\begin{aligned}
P_{w}^{s a t}\left(T^{s}\right)=\exp (73.649- & 7258.2 / T^{s}-7.3 \log \left(T^{s}\right) \\
+ & \left.4.1653 \times 10^{-6} \times T^{s^{2}}\right) ;
\end{aligned}
$$

Condensation produces heat which must be added on the right hand side of equation (7). It is positive and equal to the product of the latent heat of water condensation by the condensation rate $-L_{v w}\left(T^{s}\right) \dot{m}_{w}$. It contributes to increase the temperature of the droplet and is opposed to the cooling produced by evaporation. To simplify, the water is assumed to diffuse instantaneously into the Diethyl Ether, so that at each instant $\rho_{d}$ and $C_{p d}$ can be calculated by using the classical rules for a homogeneous mixture of liquids:

$$
\begin{array}{r}
\frac{1}{\rho_{d}}=\frac{Y_{w}}{\rho_{w}}+\frac{1-Y_{w}}{\rho_{d e}} ; \quad C_{p d}=Y_{w} C_{p w}+\left(1-Y_{w}\right) C_{p d e} \\
Y_{w}=\frac{V_{w} \rho_{l}}{\left(V_{d}-V_{w}\right) \rho_{d e}+V_{w} \rho_{l}}
\end{array}
$$

Although the ambient temperature is low and the droplet is small, the assumption adopted for the calculation (infinite heat and mass diffusion model) oversimplifies the reality. In real life, water concentration is probably higher at the droplet surface than at center, while Diethyl ether concentration is higher at the center (Sirignano 1983). With increasing time, the droplet turns into a "two-component" droplet, whose the most volatile substance, the Diethyl Ether, completely vaporizes and the non-volatile substance, the water is remaining. As long as $V_{d} \geq V_{w}$, we consider than the Diethyl Ether is not completely evaporated and the system constituted by the evaporation/condensation equations is solved. Beyond this limit, the droplet only contains water which evaporates much more slowly. This last step is simulated by solving the system constituted by equations $(5,11,20)$, the liquid phase being water and the gas phase being humid air. The results obtained for the two ambient temperatures and relative humidity are reported in Fig. 3. Whatever the conditions, the model taking condensation into account closely matches the measurements. Evaporation rates are quantitatively well reproduced as well as the droplet diameter at plateau that increases with relative humidity of the air. The falling velocity is also rather well predicted in both cases. The small differences observed asymptotically are simply due to the way the relative velocity is evaluated. The simulation was performed by assuming the air velocity around the droplet to be constant and equal to the suction velocity $u_{s u c}$, while in real life it increases when approaching the suction device. Given these simplifications, it is difficult to conclude on a possible effect of the evaporation on the drag. The results suggest, in agreement with Yuen and Chen (1976), that the drag obeys the same law as an isolated non-evaporating droplet, on condition to use the viscosity of the vapor film around the droplet to calculate the Reynolds number (eq. 18).

\section{Conclusion}

The in-line digital holography and "inverse problems" reconstruction approach tested in Chareyron et al (2012) to track evaporating freon droplets in a turbulence, has been used to measure the evaporation of Diethyl Ether droplets falling in air, from a Lagrangian point of view. The motivation of this new experiment is to complete the validation of the technique in a test case where evaporation is much higher and the absence of turbulence makes comparisons of the experimental data with simple evaporation/condensation model possible.

The holograms of Diethyl Ether droplets recorded in this situation confirm that the hologram formation is modified when evaporation takes place. The central fringe of the holograms is abnormally bright compared to what is expected with a non-evaporating droplet and a wake image is visible behind the holograms. 
These disturbances, already noted with freon, are more accurately visualized here, because the falling velocity of droplets is weak and hence, the layer of vapor around the droplets that creates the disturbances, is almost spherical. These new droplets holograms fully justify the use of the weighted mask method proposed in Chareyron et al (2012) to exclude the central part of the holograms from the reconstruction process with the "inverse problems" approach. A more detailed analysis of the disturbances, their physical origin and their processing can be found in two companion papers (Méès et al 2013; Seifi et al 2013).

The Lagrangian time evolution of the droplets diameter and velocity along their whole trajectory, from injection to the end of evaporation, has been obtained for the first time. It shows that the "inverse problems" hologram reconstruction, can be used to track the droplets till they fully evaporate and accurately determine evaporation rates and the residual water amount due to water condensation for different room conditions. The evaporation rates, the falling velocity and the residual water amount thus measured have been validated by comparing the results with a simple evaporation/condensation model. A good agreement has been found between experiments and calculation. In particular, the diameter square decreases following the same $d^{2}$ laws as predicted by the model. The presence of condensation exhibited by holography has also been validated by estimating the diameter and refractive index evolution of droplets from light scattering measurements at rainbow angle.

These results are helpful to prepare the next experiments that we plan to do in turbulent flow condition. They attest that the Diethyl Ether is a good candidate for these experiments because it evaporates very fast and it is easier to inject than freon. They also show that humid air condensation at droplet surface has a non negligible effect on the diameter evolution and must be taken into account in future works. In particular, a good control of the relative humidity of air and room temperature is essential.

Acknowledgements This work takes place in the MORIN project (3D Optical Measurements for Research and INdustry). It has been founded by the "Programme Avenir Lyon Saint-Etienne" of Lyon University in the framework of "investissement d'avenir" (ANR-11-IDEX-0007). This work has been also supported by ANR program TEC2 (Turbulence Evaporation and Condensation).

\section{References}

Abramzon B, Sirignano WA (1989) Droplet vaporization model for spray combustion calculations. Int J Heat Mass
Transf 32(9):1605-1618

Airy GB (1838) On the intensity of light in the neighbourhood of a caustic. Trans Camb Phil Soc 6(3):379-402

Bird RB, Stewart WE, Lightfoot EN (1960) Transport Phenomena. John Wiley

Birouk M, Gökalp I (2006) Current status of droplet evaporation in turbulent flows. Progr Energy Comb Sci 32(4):408-423

Bohren CF, Huffman DR (1983) Absorption and Scattering of Light by Small Particles. John Wiley \& Sons, New York

Bourgoin M, Ouellette NT, Xu H, Berg J, Bodenschatz E (2006) The role of pair dispersion in turbulent flow. Science 311:835-838

Chareyron D, Marié JL, Fournier C, Gire J, Grosjean N, Denis L, Lance M, Méès L (2012) Testing an in-line digital holography "inverse method" for the Lagrangian tracking of evaporating droplets in homogeneous nearly-isotropic turbulence. New J Phys 14, 043039

Clift R, Grace JR, Weber ME (1978) Bubbles, Drops and Particles. Academic Press

Fournier C, Denis L, Fournel T (2010) On the single point resolution of on-axis digital holography. J Opt Soc Am A 27(8):1856-1862

Fournier C, Denis L, Thiébaut E, Fournel T, Seifi M (2011) Inverse problems approaches for digital hologram reconstruction. In: ThreeDimensional Imaging, Visualization, and Display 2011, Orlando, United States, vol 8043, pp $1-14$

Frössling N (1938) Über die verdunstung fallender tropfen. Gerlands Beitr Geophys 52:170-216

Garcia-Sucerquia J, Xu W, Jericho SK, Klages P, Jericho MH, Kreuzer HJ (2006) Digital in-line holographic microscopy. Appl Opt 45(5):836-850

Gire J, Denis L, Fournier C, Thiébaut E, Soulez F, Ducottet C (2008) Digital holography of particles: benefits of the "inverse-problem " approach. M Sci Technol 19(7), 074005

Glover AR, Skippon SM, Boyle RD (1995) Interferometric laser imaging for droplet sizing: a method for dropletsize measurement in sparse spray systems. Appl Opt 34(36):8409-8421

Gopalan B, Malkiel E, Katz J (2008) Experimental investigation of turbulent diffusion of slightly buoyant droplets in locally isotropic turbulence. Phys Fluids 20(9), 095102

Green DW, Perry RH (2008) Perry's Chemical Engineer's Handbook eight edition. Mc Graw Hill

Guella S, Alexandrova S, Saboni A (2008) Evaporation d'une gouttelette en chute libre dans l'air. Int J Therm Sci $47(7): 886-898$

Han X, Ren KF, Wu ZS, Corbin F, Gouesbet G, Gréhan G (1998) Characterization of initial disturbances in liquid jet by rainbow sizing. Appl Opt 37(36):8498-8503

Han X, Ren KF, Méès L, Gouesbet G (2001) Surface waves/geometrical rays interferences: Numerical and experimental behavior at rainbow angles. Optics Commun 195(1-4):49-54

Hubbard GL, Denny VE, Mills AF (1975) Droplet evaporation: Effects of transients and variable properties. Int $\mathrm{J}$ Heat Mass Transf 18:1003-1008

Katz J, Sheng J (2010) Applications of holography in fluid mechanics and particle dynamics. Annu Rev Fluid Mech 42:531-555

Law CK (1982) Recent advances in droplet vaporization and combustion. Prog Energy Combust Sci 8(3):171-201

Law CK, Xiong TY, Wang CH (1987) Alcohol droplet vaporization in humid air. Int J Heat Mass Transf 30(7):14351443 
Lebrun D, Allano D, Méès L, Walle F, Corbin F, Boucheron R, Fréchou D (2011) Size measurement of bubbles in a cavitation tunnel by digital in-line holography. Appl Opt 50(34):H1-H9

Lu J, Fugal JP, Nordsiek H, Saw EW, Shaw RA, Yang W (2008) Lagrangian particle tracking in three dimensions via single-camera in-line digital holography. New J Phys 10,125013

Méès L, Grosjean N, Chareyron D, Marié JL, Seifi M, Fournier C (2013) Evaporating droplet hologram simulation for digital in-line holography set-up with divergent beam. J Opt Soc Am A 30(10):2021-2028

Meng X, Zheng P, Wu J, Liu Z (2008) Density and viscosity measurements of diethyl ether from 243 to $373 \mathrm{~K}$ and up to 20MPa. Fluid Phase Equilib 271:1-5

Mordant N, Lévèque E, Pinton JF (2004) Experimental and numerical study of the Lagrangian dynamics of high Reynolds turbulence. New J Phys 6:116

Nguyen D, Honnery D, Soria J (2011) Measuring evaporation of micro-fuel droplets using magnified dih and dpiv. Exp Fluids 50(4):949-959

Ragucci R, Cavaliere A, Massoli P (1990) Drop sizing by laser light scattering exploiting intensity angular oscillation in the mie regime. Part Part Syst Charact 7(1-4):221-225

Ranz WE, Marshall WR (1952) Evaporation from drops. Chem Eng Prog 48:141-146; 173-180

Reveillon J, Demoulin FX (2007) Effects of the preferential segregation of droplets on evaporation and turbulent mixing. J Fluid Mech 583:273-302

Royer H (1974) An application of high-speed microholography: the metrology of fogs. Nouv Rev Opt 5(2):87-93

Saengkaew S, Charinpanitkul T, Vanisri H, Tanthapanichakoon W, Biscos Y, Garcia N, Lavergne G, Méès L, Gouesbet G, Gréhan G (2007) Rainbow refractrometry on particles with radial refractive index gradients. Exp in Fluids 43(4):595-601

Seifi M, Fournier C, Grosjean N, Méès L, Marié JL, Denis L (2013) Accurate 3D tracking and size measurement of evaporating droplets using an in-line digital holography and "inverse problems" reconstruction approach. Opt Express 21(23), DOI:10.1364/OE.21.027964

Sirignano WA (1983) Fuel droplet vaporization and spray combustion theory. Progr Energy Comb Sci 9(4):291-322

Soulez F, Denis L, Fournier C, Thiébaut E, Goepfert C (2007a) Inverse-problem approach for particle digital holography: accurate location based on local optimization. J Opt Soc Am A 24(4):1164-1171

Soulez F, Denis L, Thiébaut E, Fournier C, Goepfert C (2007b) Inverse problem approach in particle digital holography: out-of-field particle detection made possible. J Opt Soc Am A 24(12):3708-3716

Toker GR, Stricker J (1996) Holographic study of suspended vaporizing volatile liquid droplets in still air. Int $\mathrm{J}$ Heat Mass Transf 39(16):3475-3482

Toker GR, Stricker J (1998) Study of suspended vaporizing volatile liquid droplets by an enhanced sensitivity holographic technique: additional results. Int $\mathrm{J}$ Heat Mass Transf 41(16):2553-2555

Toschi F, Bodenschatz E (2009) Lagrangian properties of particles in turbulence. Annu Rev Fluid Mech 41:375-404

Tropea C (2011) Optical particle characterization in flows. Annu Rev Fluid Mech 43:399-426

Tsilingiris PT (2008) Thermophysical and transport properties of humid air at temperature range between 0 and $100^{\circ} \mathrm{C}$. Energ Convers Manage 49(5):1098-1110
Tyler GA, Thompson BJ (1976) Fraunhofer holography applied to particle size analysis a reassessment. J Mod Opt 23(9):685-700

van Beeck JPAJ, Riethmuller ML (1996) Rainbow phenomena applied to the measurement of droplet size and velocity and to the detection of nonsphericity. Appl Opt 35(13):2259-2266

van de Hulst HC (1957) Light scattering by small particles. John Wiley \& Sons, New York

Vikram CS, Billet ML (1988) Some salient features of inline fraunhofer holography with divergent beams. Optik $78(2): 80-83$

Volk R, Mordant N, Verhille G, Pinton JF (2008) Laser Doppler measurement of inertial particle and bubble accelerations in turbulence. EPL 81, 34002

Voth GA, Laporta A, Crawford AM, Alexander J, Bodenschatz E (2002) Measurement of particle acceleration in fully developed turbulence. J Fluid Mech 469:121-160

Wassiljewa A (1904) Wärmeleitung in gasgemischen. Physikalische Zeitschrift, 5(22):737-742

Wilke CR (1950) A viscosity equation for gas mixtures. J Chem Phys 18(4):517

Yuen M, Chen LW (1976) On drag of evaporating droplets. Combut Sci and Technol 14(4-6):147-154 